\title{
PERBEDAAN WAKTU CLEARANCE IMPOR SEBELUM DAN SESUDAH IMPLEMENTASI PUSAT LOGISTIK BERIKAT (PLB)
}

Raden Didiet Rahmat Hidayat ${ }^{1)}$, Mohammad Iqbal Firdaus ${ }^{2)}$, Lis Lesmini ${ }^{3)}$, Endang Sugiharti ${ }^{4)}$, Latifah Dwi Handayani $^{5)}$

1) Program Studi Vokasi Manajemen Logistik dan Material, Institut Transportasi dan Logistik Trisakti

2) Program Studi Manajemen, Institut Transportasi dan Logistik Trisakti

${ }^{3)}$ Program Studi Manajemen, Institut Transportasi dan Logistik Trisakti

4) Program Studi Manajemen, Institut Transportasi dan Logistik Trisakti

${ }^{5)}$ Program Studi Manajemen, Institut Transportasi dan Logistik Trisakti

Email : ${ }^{1)}$ didiet.hidayat@yahoo.com, ${ }^{2)}$ iqbal.firdaus@ gmail.com, ${ }^{3)}$ lies1969@yahoo.com,${ }^{4}$ artisuli21@yahoo.com 5) $\underline{\text { latifahldh@gmail.com }}$

\begin{tabular}{ll} 
ARTICLE INFO & ABSTRACT \\
\hline Keywords: & Pusat Logistik Berikat (PLB) or The Bonded Logistics Center is part of the \\
Bonded Logistics Center, & Government's Economic Policy Package issued in September 2015. This clarified by \\
Customs Clearance Time & Regulation of the Minister of Finance No. 272 of 2015 on Bonded Logistics Center \\
& (PLB) plus the Regulation of the Director General of Customs and Excise No. 1 of \\
& 2016, Regulation of the Director General of Customs and Excise No. 2 of 2016 and \\
& Regulation of the Director General of Customs and Excise No. 3 of 2016. The \\
& Implementation of Bonded Logistics Center (PLB) has managed to reduce the \\
& clearance time process from 4 days to 1.8 days.
\end{tabular}

\section{PENDAHULUAN}

Pemerintah telah mengeluarkan Paket Kebijakan Ekonomi Kedua pada 29 September 2015 yang pada intinya melakukan deregulasi dan debirokratisasi untuk mempermudah investasi baik melalui Penaman Modal Dalam Negeri (PMDN) maupun melalui Penanaman Modal Asing (PMA). Pada bagian keempat paket tersebut menetapkan bahwa pemerintah memberikan insentif fasilitas di kawasan Pusat Logistik Berikat yang selanjutnya disebut PLB maka perusahaan manufaktur tidak perlu impor dan tidak perlu mengambil barang dari luar negeri karena cukup mengambil dari PLB. (Ministry, National, Competitiveness, \& Haryana, 2017)

PLB adalah bangunan, tempat atau kawasan yang memenuhi persyaratan tertentu yang digunakan untuk menimbun barang asal luar daerah Pabean dan/atau barang yang berasal dari tempat lain dalam daerah Pabean, dapat disertai 1 (satu) atau lebih kegiatan sederhana dalam jangka waktu tertentu untuk dikeluarkan kembali. (Rizaldy, Wynd, Hidayat, Raden Didiet Rachmat, Handayani, 2018)

Untuk mendukung pelaksanaan PLB maka pemerintah telah menetapkan beberapa peraturan dan perundangan yang terkait: 
- Paket Kebijakan Ekonomi Kedua, September 2015 (Bappenas, 2015)

- Peraturan Pemerintah Republik Indonesia Nomor 85/2015, 25 November 2015 Tentang Perubahan Atas Peraturan Pemerintah Nomor 32 Tahun 2009 Tentang Tempat Penimbunan Berikat (Pemerintah et al., 2015)

- Peraturan Menteri Keuangan Republik Indonesia Nomor 272/PMK.04/2015, 31 Desember 2015 Tentang Pusat Logistik Berikat (Kementerian Keuangan, 2015)

- Peraturan Direktur Jenderal Bea dan Cukai Nomor PER-1/BC/2016 29 Januari 2016 Tentang Tata Laksana Pusat Logistik Berikat (B. dan C. Direktur Jenderal, 2016a)

- Peraturan Direktur Jenderal Bea dan Cukai Nomor PER- 2/BC/2016 29 Januari 2016 Tentang Tata Laksana Pengeluaran Barang Impor Dari Kawasan Pabean Untuk Ditimbun di Pusat Logistik Berikat (B. D. C. Direktur Jenderal, 2016)

- Peraturan Direktur Jenderal Bea dan Cukai Nomor PER-3/BC/2016 29 Januari 2016 Tentang Tata Laksana Pengeluaran Barang Impor Dari Pusat Logistik Berikat Untuk Diimpor Untuk Dipakai (B. dan C. Direktur Jenderal, 2016b)

- Peresmian 11 Pusat Logistik Berikat oleh Presiden Republik Indonesia 10 Maret 2016 (Akuntono, 2016)

Menurut UU No 17 Tahun 2006 tentang Kepabeanan yang dimaksud dengan impor adalah kegiatan memasukkan barang ke dalam daerah pabean dan dengan kehadiran PLB diharapkan akan mempercepat waktu clearance bagi para pengguna fasilitas PLB.

Penelitian ini bertujuan untuk mengetahui perbedaan waktu clearance impor sebelum dan sesudah implementasi PLB.

\section{METODE PENELITIAN}

Pendekatan penelitian ini bersifat kualitatif untuk menggambarkan secara mendalam bagaimana PLB dapat menurunkan waktu dan biaya logistik untuk meningkatkan daya saing.

Pengumpulan data dilakukan melalui wawancara terstruktur, semi terstruktur dan in-depth interview dan focus group discussion.

Sumber data dalam penelitian ini adalah para informan yang memiliki kapabilitas dan kompetensi sehingga informasi yang diberikan kredibel dan sesuai dengan kebutuhan penelitian ini (purposive).

Narasumber dalam penelitian ini adalah:

1. Widiyanto (Narasumber 1) 
Beliau adalah General Manager Warehouse \& Contract Logistics PT. Agility dan juga Sekretaris PPLBI (Perkumpulan Pusat Logistik Berikat Indonesia).

2. Ety Puspitasari (Narasumber 2)

Beliau adalah Ketua Umum PPLBI.

Teknik analisis data yang digunakan dalam penelitian ini menggunakan pendekatan yang dikembangkan oleh Miles dan Huberman yang meliputi (setelah pengumpulan data) reduksi data, pemisahan data dari yang tidak fokus, terlalu terperinci dan lain-lain sehingga data tersebut akan menampakkan pola atau tema.

Selanjutnya adalah menampilkan data (data display) yang berfungsi untuk membantu memahami untuk analisis lanjutan terhadap suatu informasi atau event.

Proses yang terakhir adalah penarikan kesimpulan yang dilakukan peneliti berdasarkan pola dan temanya. Penarikan kesimpulan dilakukan secara berkesinambungan, yaitu sambil dilakukan pada saat reduksi data dan tampilan data dilakukan. (Miles, Huberman, \& Saldana, 2014)

\section{Gambar II.1. Teknik Pengolahan Data}

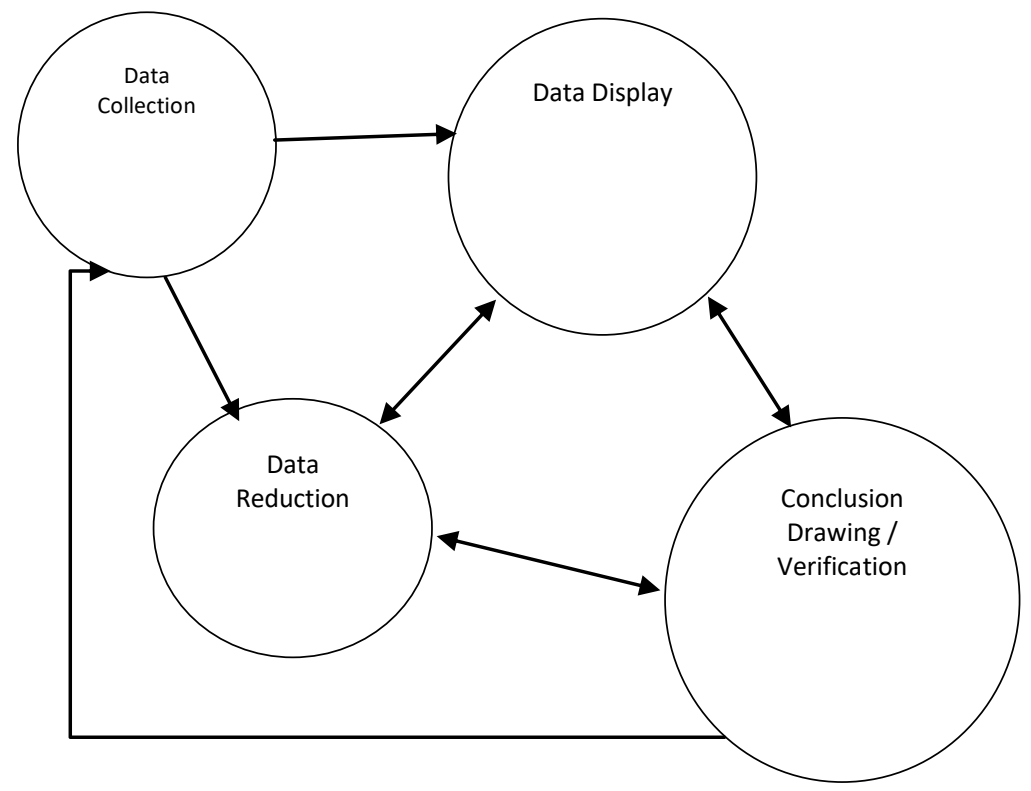

Sumber: Miles, Huberman, \& Saldana (2014) 


\section{HASIL DAN PEMBAHASAN}

\section{A . Analisis Proses Clearance Impor Sebelum Menggunakan Fasilitas PLB Secara Umum}

Gambar III.1

Proses Clearance Impor Sebelum Menggunakan Fasilitas PLB

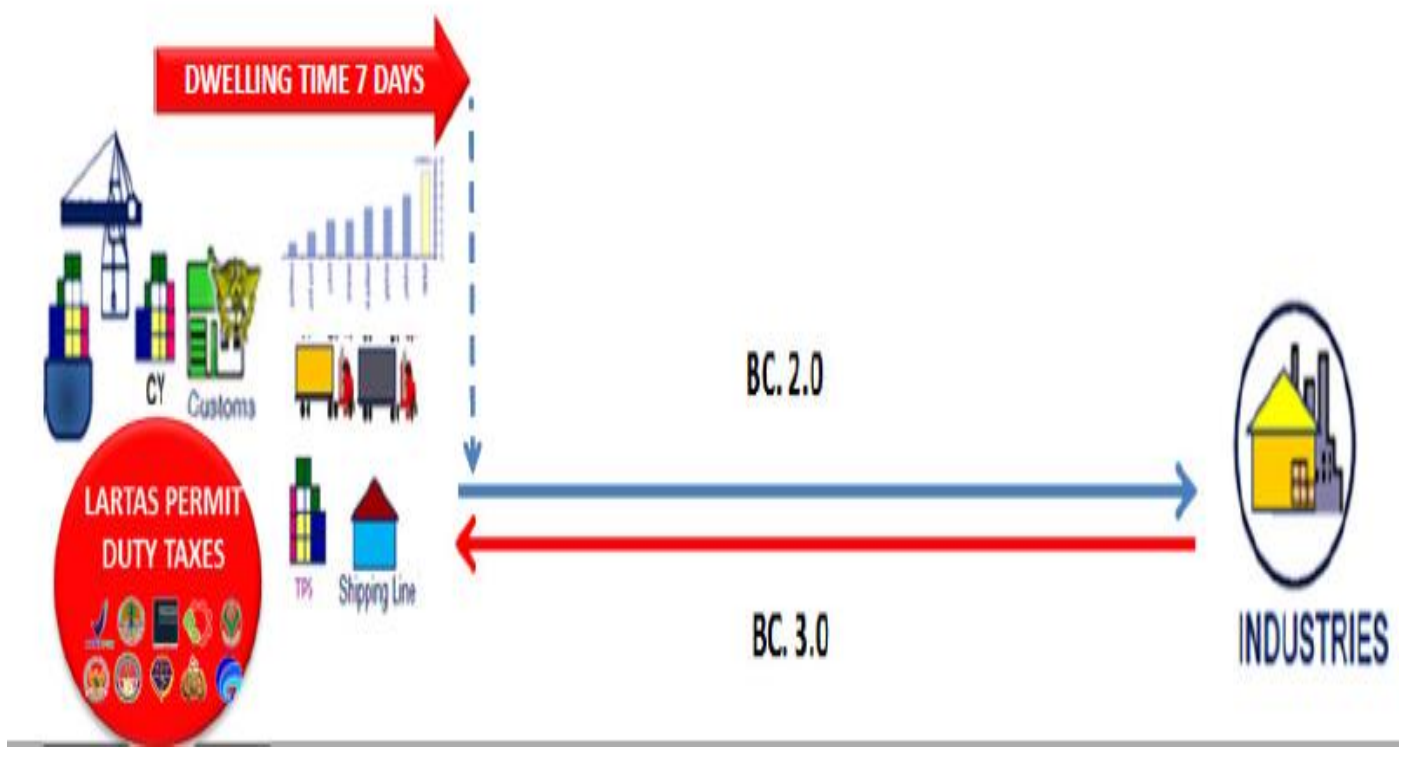

Sumber: PT. Agility International (2016)

Peti kemas atau kargo yang diangkut oleh kapal atau sarana pengangkut lainnya menuju ke wilayah pabean Indonesia akan melalui beberapa tahap sebagaimana ditunjukkan pada Gambar III.1 sebagai berikut:

a) Kapal datang di perairan Indonesia kemudian menunggu antrian untuk sandar di dermaga.

b) Kapal sandar di dermaga, pihak shipping line menyampaikan inward manifest (manifest kedatangan sarana pengangkut)/BC 1.1, kemudian peti kemas di bongkar dari kapal (unloading).

c) Peti kemas yang sudah dibongkar kemudian ditimbun di lapangan penumpukan container (container yard/CY). Importir menyiapkan formulir BC 2.0 pemberitahuan Impor Barang (PIB) jika importir ingin mengimpor barang untuk dipakai.

d) Tahap penyelesaian kewajiban pabean (customs clearance) yang meliputi verifikasi dokumen oleh bea cukai, pemeriksaan persyaratan impor (larangan dan pembatasan), pemeriksaan fisik peti kemas (khusus jalur merah) dan penerbitan Surat Persetujuan Pengeluaran Barang (SPPB).

e) Melakukan pembayaran biaya penimbunan ke operator pelabuhan (post clearance).

f) Peti kemas keluar dari kawasan pelabuhan. 


\section{B. Analisis Proses Clearance Impor Sesudah Menggunakan Fasilitas PLB}

\section{Gambar III.2}

Proses Clearance Impor Sesudah Menggunakan Fasilitas PLB

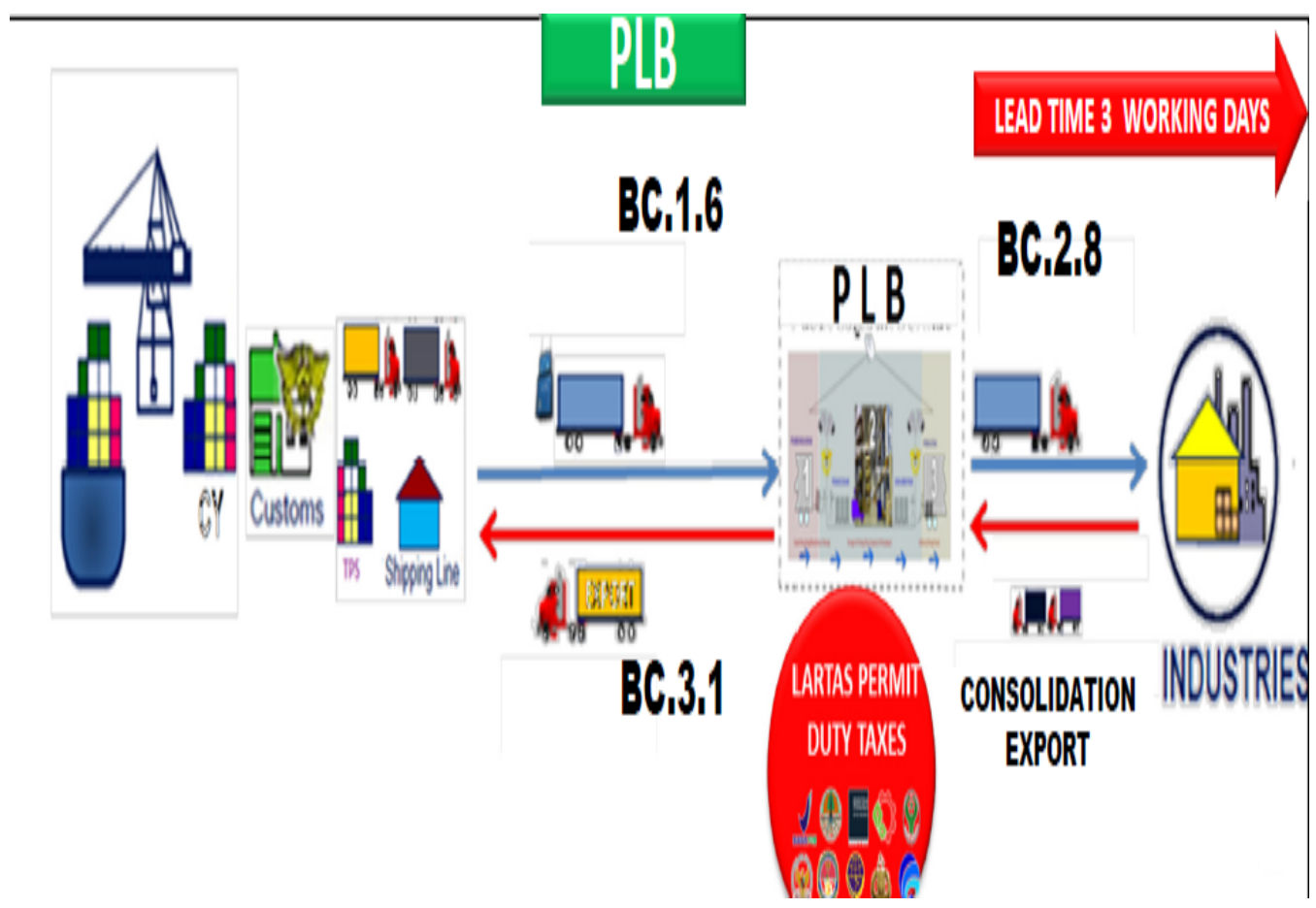

Sumber: PT. Agility International Tahun 2016

Penjelasan:

a) Kapal datang di perairan Indonesia kemudian menunggu antrian untuk sandar di dermaga.

b) Kapal sandar di dermaga, pihak shipping line menyampaikan inward manifest (manifest kedatangan sarana pengangkut)/BC 1.1, kemudian peti kemas di bongkar dari kapal (unloading).

c) Peti kemas yang sudah di bongkar kemudian ditimbun di lapangan penumpukan container (container yard/CY). Importir menyiapkan dan mengajukan pemberitahuan pabean $\mathrm{BC}$ 1.6. Tahap ini disebut juga tahap pre-clearance.

d) Proses customs clearance akan ditunda yang pelaksanaannya bukan di Pelabuhan namun di PLB. Selanjutnya jika form BC 1.6 sudah diverifikasi, akan diterbitkan SPPB PLB.

e) Pembayaran biaya penimbunan ke operator pelabuhan (post clearance).

f) Pengeluaran peti kemas dari kawasan pelabuhan dan pemasangan tanda pengaman pada peti kemas (post clearance).

g) Penyelenggara PLB, Pengusaha PLB, dan Pengusahaan Dilakukan oleh Pengusaha PLB (PDPLB) memasukkan barang ke PLB dengan mencocokkan kriteria-kriteria yang tercantum pada SPPB PLB, kemudian melaporkan ke Kantor Pengawas Pabean untuk mendapatkan Surat Persetujuan Penyelesaian Dokumen (SPPD). 
h) Dengan form BC 2.8, pelaku usaha dalam industri mengimpor barang dari PLB untuk keperluan industrinya. Pada tahap ini pelaku usaha tersebut membayar bea masuk, cukai dan PDRI sesuai nilai pabeannya. Pelaku usaha yang membeli juga mempersiapkan persyaratan impor dari Kementerian teknis untuk barang yang terkena aturan pembatasan.

\section{Kelebihan dan Kekurangan Sesudah Menggunakan Fasilitas PLB}

Berikut adalah kelebihan dan kekurangan:

a) Kelebihan:

1) Perizinan-perizinan dengan instansi terkait dapat diselesaikan setelah muatan dikeluarkan dari Pelabuhan dan selama muatan berada di gudang Pusat Logistik Berikat.

2) Bea masuk dan pajak impor ditangguhkan.

3) Jika ada pemeriksaan karantina muatan tetap bisa keluar dari Pelabuhan dan kegiatan pemeriksaan karantina bisa dilakukan di dalam PLB.

4) Biaya storage atau port charges lebih kecil dan business waste turun.

5) Jika customer kehabisan atau kekurangan raw material dan packaging material dapat mengambil atau order dari PLB yang jangka waktu nya lebih cepat tidak sampai bermingguminggu atau berbulan-bulan dibandingkan jika order ke supplier yang ada di luar negeri.

6) PT. Agility International memiliki bidang usaha baru dengan menjual jasa gudang, jasa trucking serta jasa customs clearance nya.

7) Penyerapan tenaga kerja baru yang lebih banyak.

8) Business Enviroment untuk PT. Agility International.

b) Kekurangan:

1) Harus menunggu adanya BC 1.1 yang di release oleh carrier atau Perusahaan Pelayaran jika ingin mentransfer PIB untuk mendapatkan respon karena PLB mandatory dengan BC 1.1 artinya keuntungan untuk pre-notification yang biasa didapatkan dari fasilitas MITA tidak berlaku.

2) Banyak fasilitas yang didapatkan saat status importir MITA menjadi hilang karena shipment menggunakan PLB.

3) Harus menyerahkan Surat Keterangan Asal (Certificate of Origin) beserta Dokumen Pelengkap Pabean ke Kantor Pengawas, paling lama 3 (tiga) hari kerja sejak tanggal SPPB PLB.

4) Dokumentasi lebih banyak.

5) Sistem modul Bea Cukai masih sering bermasalah.

6) PT. Agility International mengeluarkan invest yang cukup besar untuk memperoleh izin fasilitas PLB dan dalam mengelola bidang usaha ini.

7) PT. Agility International harus menerapkan sistem shift kepada karyawan nya. 


\section{Waktu Clearance Sesudah Menggunakan Fasilitas PLB}

Waktu Logistik meliputi berapa lama waktu pengiriman bahan baku dari pemasok ke industri pemesan barang yang meliputi: a) Waktu pengiriman dari pemasok sampai ke pelabuhan penerima. b) Waktu pengiriman dari pelabuhan penerima ke lokasi penyimpan sementara (jika ada, atau pada ssat ada PLB maka sampai ke lokasi PLB). C) Waktu pengiriman dari tempat penyimpanan sementara dari tempat penyimpanan sementara (dari PLB jika sudah ada PLB) sampai ke penerima. (Republik Indonesia, 2017)

Adanya pemangkasan waktu clearance dari 4 hari menjadi 1,8 hari dipaparkan oleh Bapak Widiyanto dari PT. Agility dan hal ini diperkuat dengan pernyataan dari Ibu Ety Puspitasari selaku Ketua Umum Perhimpunan Pusat Logistik Berikat Indonesia (PPBLI) serta pernyataan dari Bapak Heri Pambudi selaku Dirjen Bea \& Cukai Republik Indonesia yang juga menyatakan hal yang sama akan adanya pemangkasan waktu tersebut. (Afrianto, 2017)

Hal ini terjadi karena semakin singkatnya waktu untuk mengurus izin dan dokumen lainnya. Perizinanperizinan dengan instansi terkait dapat diselesaikan setelah muatan dikeluarkan dari Pelabuhan dan selama muatan berada di gudang. (Pusat Logistik Berikat Indonesia, 2016)

\section{SIMPULAN DAN SARAN}

Dari hasil penelitian diatas diperoleh hasil sebagai berikut:

1. Penurunan waktu waktu clearance dari 4 hari menjadi 1,8 hari setelah menggunakan fasilitas PLB

2. Penggunaan form BC 1.6, BC 3.1. dan BC 2.8 untuk menggunakan fasilitas PLB.

Adapun saran yang perlu kami sampaikan adalah penggunaan e-DO (electronic-Delivery Order) yang terkoneksi sesama instansi untuk mempercepat waktu clearance dan menjadikan Indonesia Hub Logistik Asia Pasifik. (Republika.co.id, 2017)

\section{DAFTAR PUSTAKA}

Afrianto, D. (2017). Logistik Berikat, Proses Clearance Dipangkas dari 4 Hari Jadi 1,8 Hari. Retrieved from https://economy.okezone.com/read/2017/04/12/320/1665628/logistik-berikat-proses-clearancedipangkas-dari-4-hari-jadi-1-8-hari

Akuntono, I. (2016). Jokowi Resmikan Pusat Logistik Berikat di Jakarta Utara. Kompas.Com. Retrieved from http://ekonomi.kompas.com/read/2016/03/10/094340826/Jokowi.Resmikan.Pusat.Logistik.Berikat.di.Ja karta.Utara

Bappenas. (2015). Paket Kebijakan Ekonomi. Bappenas.Go.Id. Retrieved from http://www.bappenas.go.id/id/data-dan-informasi-utama/publikasi/paket-kebijakan-ekonomi

Direktur Jenderal, B. D. C. PER-02/BC/2016 tentang Tata Laksana Pengeluaran Barang Impor Dari Kawasan Pabean Untuk Ditimbun Di Pusat Logistik Berikat, 2016 § (2016). Jakarta. 
Direktur Jenderal, B. dan C. PER-01/BC/2016 tentang Tata Laksana Pusat Logistik Berikat (2016). Jakarta. Retrieved from www.beacukai.go.id

Direktur Jenderal, B. dan C. PER-03/BC/2016 tentang Tata Laksana Pengeluaran Barang Impor Dari Pusat Logistik Berikat Untuk Dimpor Untuk Dipakai, 2015 § (2016). Retrieved from www.beacukai.go.id

Kementerian Keuangan. PMK-272-Tahun-2015 tentang Pusat Logistik Berikat (2015). Jakarta. Retrieved from www.kemenkeu.go.id

Miles, M. B., Huberman, M. a, \& Saldana, J. (2014). Drawing and Verying Conclusions. Qualitative Data Analysis: A Methods Sourcebook, 275-322. https://doi.org/January 11, 2016

Ministry, A. H., National, P., Competitiveness, I., \& Haryana, A. (2017). Peran Pusat Logistik Berikat ( PLB ) Dalam Menurunkan Dwelling Time di Pelabuhan Indonesia, (January).

Pemerintah, P., Indonesia, R., Tempat, T., Berikat, P., Rahmat, D., Yang, T., ... Indonesia, P. R. Perubahan Atas Peraturan Pemerintah Nomor 32 Tahun 2009 tentang Tempat Penimbunan Berikat (2015). Jakarta.

Pusat Logistik Berikat Indonesia, P. (2016). Perhimpunan Pusat Logistik Berikat Indonesia. Retrieved from http://www.pplbi.or.id/

Republik Indonesia, K. P. (2017). Laporan Akhir Kajian Evaluasi Manfaat Pusat Logistik Berikat Dalam Mendukung Daya Saing Industri Nasional. Jakarta.

Republika.co.id. (2017). Pusat Logistik Berikat Bersiap Menjadi Hub Logistik Asia Pasifik. Retrieved from http://www.pplbi.or.id/news/view/pusat_logistik_berikat_bersiap_menjadi_hub_logistik_asia_pasifik

Rizaldy, Wynd, Hidayat, Raden Didiet Rachmat, Handayani, L. D. (2018). Manajemen Rantai Pasok dan Logistik (Berdasarkan Aturan Nasional, Internasional dan Review Para Pakar) (1st ed.). Bogor: In Media.

Retrieved

from

http://sinta2.ristekdikti.go.id/books?q=manajemen+rantai+pasok+dan+logistik\&search=1 